\title{
A EDUCAÇÃO PARA O TRABALHO NOS SISTEMAS PRISIONAIS PAULISTAS
}

\author{
EDUCATION FOR WORK IN PRISON SYSTEMS IN SÃO PAULO \\ LA EDUCACIÓN PARA EL TRABAJO EN LOS SISTEMAS PENITENCIARIOS PAULISTAS
}

\author{
SILVA JUNIOR, João Ferreira da ${ }^{1}$ \\ ALANIZ, Erika Porceli2
}

\begin{abstract}
RESUMO
Discutimos, neste artigo, a materialização do PET (Programa de Educação para o Trabalho) desenvolvido pela FUNAP. Trata-se de uma pesquisa empírica, com análise bibliográfica e documental, realizada em três unidades do sistema penitenciário, localizadas em um município do interior do Estado de São Paulo. Foram realizadas observações sistemáticas nas instituições e entrevistas semiestruturadas com os gestores e monitores que atuam no planejamento e na implementação do PET. A análise evidenciou que a formação profissional proposta não se efetiva nas unidades carcerárias devido à determinadas circunstâncias, como a reduzida carga horária dos cursos, a ausência de infraestrutura para aulas, e o reduzido número de detentos atendidos.

Palavras chave: Educação e trabalho. Educação e privação de liberdade. Reinserção produtiva e social.
\end{abstract}

\section{ABSTRACT}

We discuss, in this article, the materialization of PET developed by FUNAP. It is an empirical research, with bibliographical and documentary analysis, carried out in three units of the penitentiary system located in a municipality of the interior of the State of São Paulo. Systematic observations were made in the institutions and semi-structured interviews with the managers and monitors involved in PET planning and implementation. The analysis showed that the professional training offered is not effective in the prison units due to the reduced hours of classes, the lack of infrastructure for classes, and the reduced number of prisoners attended.

Keywords: Education and work. Education and deprivation of liberty. Productive and social reintegration.

\section{RESUMEN}

Discutimos, en este artículo, la materialización del PET desarrollado por FUNAP. Se trata de una investigación empírica, con análisis bibliográfico y documental, realizada en tres unidades del sistema penitenciário, ubicadas en un municipio del interior del Estado de São Paulo. Se realizaron observaciones sistemáticas en las instituciones y entrevistas semiestructuradas con los gestores y monitores que actúan en la planificación y la implementación del PET. EI análisis evidenció que la formación profesional propuesta no se efectúa en las unidades carcelarias debido a circuntancias determinadas, como la reducida carga horaria de los cursos, la ausencia de infraestructura para clases, y el reducido número de detenidos atendidos.

Palabras clave: Educación y trabajo. Educación y privación de libertad. Reinserción productiva y social.

\section{INTRODUÇÃO}

\footnotetext{
${ }^{1}$ Universidade do Oeste Paulista-UNOESTE. Presidente Prudente/SP. Brasil.

${ }^{2}$ Universidade Estadual de Mato Grosso do Sul - UEMS. Campo Grande/MS. Brasil.
} 
A prisão, desde sua gênese, não tem cumprido o papel de combate à criminalidade. Historicamente, as prisões têm se caracterizado como um depósito de seres humanos, principalmente pobres, os quais antes de serem encarcerados, eram segregados nas periferias das cidades sem o mínimo de oportunidades de ascensão social. (WACQUANT, 2007; 2011, ONOFRE, 2007; 2009; JULIÃO, 2009).

O discurso de reabilitação e reintegração sociais, pertinentes às pessoas privadas de liberdade, dissimula o caráter prioritariamente punitivo das prisões, que figuram como as instituições mais requeridas para a pacificação e controle sociais, com vistas a propiciar o disciplinamento dos indivíduos. Com o objetivo contraditório de reabilitar, e ao mesmo tempo punir, a prisão entra em um paradoxo e as políticas públicas elaboradas acabam não atingindo os objetivos declarados. Um desses paradoxos está na difusão do discurso de reabilitação, incluindo a ideia de acesso à educação nos presídios (BRASIL 2010) concomitante à prática de endurecimento das penas privativas de liberdade e à diminuição dos benefícios carcerários, culminando na superlotação dos cárceres.

A região de Presidente Prudente, local de realização da pesquisa, concentra a maior população carcerária e o maior número de penitenciárias do Brasil. Em decorrência da política de interiorização dos presídios, implantada pela Secretaria de Segurança Pública do Estado de São Paulo, houve a ampliação de 37 unidades prisionais, implicando na ampliação do atendimento de saúde, trabalho, assistência jurídica, assistência social e educacional aos presos e familiares. Em 2016, havia 1283 presos em regime fechado e 273 presos em regime semiaberto na Penitenciária de Presidente Prudente. (SILVA JR, 2016).

Várias cidades estruturam o comércio, as atividades produtivas e de serviços, a fim de atender a demanda gerada pelos presídios, como por exemplo, a cidade de Pracinha que, ao ser emancipada em 30 de dezembro de 1993, contava com uma população de 1.413 habitantes, incluindo a população rural. Os dados do IBGE (2000) e da Secretaria de Administração Penitenciária (SAP, 2016) indicam haver 1893 presos somente no presídio da cidade, sendo maior que a população total do município. Assim, os presídios das cidades do interior do Estado de São Paulo, a priori, deram sustentação econômica a essas pequenas cidades, como demonstrou Watanabe (2011).

Diante da vultosa população carcerária e das ações educativas sustentadas pelo discurso de reabilitação, a pesquisa buscou demonstrar, com base nas concepções dos monitores e gestores, como se configura a educação para o trabalho, oferecida aos indivíduos privados de liberdades, promovida pelo Programa de Educação para o Trabalho e Cidadania (PET) nas unidades prisionais do município de Presidente Prudente.

A relevância deste estudo está na representatividade dessa experiência no sistema prisional do estado de São Paulo. Apesar das especificidades locais, os aspectos encontrados, nas unidades prisionais pesquisadas, apresentam-se nas demais unidades do mesmo estado, uma vez que todas seguem as mesmas diretrizes relativas à organização e ao trabalho educativo.

\section{MÉTODO}


Foram realizadas as análises bibliográfica e documental, bem como uma pesquisa empírica. A análise bibliográfica desenvolveu-se por meio do levantamento, seleção e análise das bibliografias especializadas na temática estudada, disponíveis nas bases scielo e ibict. Além disso, amparamos a análise teórica principalmente em Wacquant $(2007 ; 2010 ; 2011)$, já que em sua teoria discute-se o binômio desigualdade social e prisão da miséria. O levantamento e análise documentais foram realizados por meio da análise das principais legislações que regulamentam a educação nos presídios, bem como por meio dos documentos que orientam a educação para o trabalho na FUNAP e do Projeto Pedagógico do Curso (PPC) do PET.

Os dados coletados e analisados foram obtidos por meio de entrevistas semiestruturadas, individuais, e por meio de observação na Penitenciária de Presidente Prudente, no Centro de Ressocialização de Presidente Prudente (CR) e na Regional da FUNAP. Foram selecionados cinco funcionários para a realização da entrevista estruturada, entre eles, gestores e monitores de educação das unidades prisionais. Uma das monitoras de educação selecionada não pôde ser entrevistada por ordem superior.

\section{A EDUCAÇÃO EM AMBIENTE RESTRITIVO DE LIBERDADE}

O Brasil, nos últimos anos, aumentou significativamente o número de sua população carcerária. O relatório consolidado do Departamento Penitenciário (BRASIL, 2017) demonstra que, se tivermos como referência o ano de 1990 a 2016, há um aumento constante, em termos absolutos e relativos, da população carcerária, que salta de 90 mil presos, em 1990, para 726.712 mil, em 2016.

Há uma tendência mundial para o encarceramento, em que mesmo as atitudes não criminosas resultam em detenção. Tal realidade conduz a uma banalização da pena de prisão ou, como relatou Wacquant (2010), o encarceramento é uma maneira de controlar a população marginalizada e uma forma de remediar os problemas sociais.

\footnotetext{
A penalidade neoliberal apresenta o seguinte paradoxo: pretende remediar com um "mais Estado" policial e penitenciário o "menos Estado" econômico e social que é a própria causa da escalada generalizada da insegurança objetiva e subjetiva em todos os países, tanto no primeiro como no segundo mundo. (WACQUANT, 2010, p. 9).
}

Ao entrar na prisão, a princípio, o indivíduo não deixa de ser sujeito de direitos sociais, uma vez que, apesar de estar preso, pressupõe-se que em algum momento ele retornará à sociedade. Nesse sentido, a perda dos direitos civis é provisória e, ao retornar à liberdade, ele precisa de condições para se inserir socialmente. É preciso que esse sujeito sinta-se aceito, acolhido e tenha o senso de pertencimento, caso contrário, a ida para a prisão irá apenas acentuar um comportamento criminoso ora adquirido.

A prisionalização dificulta os esforços em favor da ressocialização; além disso, em vez de devolver à liberdade indivíduos educados para a vida social, devolve para a sociedade 
delinquentes mais perigosos, com elevado índice de possibilidade para a reincidência. (ONOFRE, 2007, p. 14).

Onofre (2007) menciona a contradição implícita na ideia de conduzir os indivíduos para a prisão a fim de serem educados, uma vez que a trajetória de vida das pessoas privadas de liberdade evidencia que, muitas delas, nunca tiveram a oportunidade de acesso à educação. Vale reiterar que a educação, ainda que atrás das grades, é um direito do preso, como explicitado por Carreira e Carneiro (2009, p. 9):

\begin{abstract}
As pessoas encarceradas, assim como todos os demais seres humanos, têm o direito humano à educação. A Declaração Universal dos Direitos Humanos reconhece o direito humano à educação em seu artigo 26 e estabelece que o objetivo dele é o pleno desenvolvimento da pessoa humana e o fortalecimento do respeito aos direitos humanos. Entende-se que os direitos humanos são universais (para todos e todas), interdependentes (todos os direitos humanos estão relacionados entre si e nenhum tem mais importância que outro), indivisíveis (não podem ser fracionados) e exigíveis frente ao Estado em termos jurídicos e políticos.
\end{abstract}

A Lei de Execução Penal (LEP) n 7.210, de 11 de julho de 1984, em seu art. 41, Inciso VII, descreve a educação como um direito do preso. Em 2010, o Conselho Nacional de Educação (CNE) aprovou o Parecer CNE/MEC/SECAD nº2 de 2010 (BRASIL, 2010), o qual orientou a oferta de educação nas prisões, regulamentando a responsabilidade, o financiamento, as ações complementares, o envolvimento da comunidade e familiares, a formação de especialista em educação nas prisões, entre outros aspectos. A Constituição Federal de 1988 (BRASIL, 1988), que assegura a educação como direito de todos, e a existência de outros instrumentos legais, que regulamentam a educação nas prisões, indicam que esse direito não pode ser utilizado como um benefício aos presos mais comportados, mas deve ser concebido como uma necessidade inerente à vida humana.

A partir dessa concepção, a escola nas prisões deve possibilitar ao ser humano sentenciado a oportunidade de reflexão e de acesso ao conhecimento, e não apenas a punição que prevalece na instituição. A escola talvez possa vir a ser, para os encarcerados, a única alternativa de espaço de discussão das relações humanas, de forma mais filosófica, racional e crítica, e que possibilite, também, por parte dos reeducandos, uma autoanálise. Para Onofre (2007, p. 21) "[...], buscar a escola para ampliar conhecimento é uma maneira de resistir ao processo de perdas que a prisão submete o indivíduo."

É verdade que a educação nas prisões gera grandes desafios a serem superados, principalmente quando se tem como referência a educação libertadora, uma vez que a submissão dos presos à imposição de regras disciplinares, assim como a hostilidade com que são tratados (VARELA, 1999) e o confinamento ao qual estão submetidos, dificulta que os reeducandos assumam a direção de suas vidas e retornem ao convívio social de forma mais autossuficiente. Por essa razão, os professores, que atuam no presídio, devem considerar a especificidade das condições ao realizar a práxis pedagógica nesse ambiente, pois, de acordo com Onofre (2009), a educação no contexto prisional é necessária para promover mudanças de atitudes e contribuir para a reintegração. 
Onofre (2007) e Julião (2009) mencionam que a educação, em várias unidades prisionais, não tem a infraestrutura necessária para que seja possível executar um trabalho pedagógico de qualidade, uma vez que existe, por parte da administração penitenciária, a preferência pelo trabalho produtivo em detrimento do estudo. Nas unidades prisionais, o trabalho é visto como uma extensão da pena e, muitas vezes, as aulas são deixadas de lado o máximo possível, e muitos alunos presos são excluídos da escola pelos próprios agentes de segurança, já que a escola é vista, pelos funcionários do presídio, como benefício que pode ser extinto a qualquer momento. Na implementação de políticas públicas, subjacente ao discurso de reintegração, evidencia-se a dissonância de posição, em relação ao trabalho e à educação, recompondo-se, na maioria das vezes, a tolerância que prioriza o trabalho dos reeducandos e não a educação. Julião (2011, p. 192) descreve da seguinte forma:

Como podemos observar, a educação e trabalho são duas importantes categorias que permeiam toda a discussão sobre programa de ressocialização ou reinserção social no sistema penitenciário. Sempre foram vistos de formas diferentes na implementação de políticas públicas de execução penal. Enquanto uns agentes operadores da execução penal - a grande maioria valoriza o trabalho como proposta de programa de "ressocialização", outros valorizam a educação. Hoje, há outro grupo que acredita que a educação e o trabalho devem estar articulados.

Evidencia-se que o trabalho na prisão é considerado como a forma prioritária de reinserção do indivíduo no tecido social, e isso explica o fato dos cursos de qualificação profissional serem facilmente aceitos nas unidades prisionais. Em decorrência da sobrevalorização do trabalho, a FUNAP, no ano de 2013, criou o PET, definindo-o como política de Estado (PPC, 2013).

\section{A EDUCAÇÃO PARA O TRABALHO OFERECIDO PELA FUNAP}

A FUNAP foi instituída pela Lei $n^{\circ} 1.238$, de 23 de dezembro de 1976, com objetivo de qualificar os presos, criar postos de trabalho remunerados dentro dos presídios e comercializar os produtos produzidos por eles. $\mathrm{O}$ artigo $3^{\circ}$ da referida lei especificava que:

A Fundação terá por objetivo contribuir para a recuperação social do preso e para a melhoria de suas condições de vida, através da elevação do nível de sanidade física e moral, do adestramento profissional e do oferecimento de oportunidade de trabalho remunerado, propondose, para tanto, a:

I. concorrer para melhoria do rendimento do trabalho executado pelos presos;

II. oferecer ao preso novos tipos de trabalho, compatíveis com sua situação na prisão;

III. proporcionar formação profissional do preso, em atividades de desempenho viável, após a sua liberação; [...]

VI. concorrer para aperfeiçoamento das técnicas de trabalho, com vistas à melhoria, qualitativa $\mathrm{e}$ quantitativa, da produção dos presídios, com a elaboração de planos especiais para as atividades industriais, agrícolas e artesanais, promovendo a comercialização do respectivo produto, com sentido empresarial [...]. (ESTATUTO, 1976, p. 3). 
Os trechos selecionados permitem inferir que há maior ênfase na busca por melhorar a produtividade do trabalho realizado pelo preso, dentro do presídio, fato evidenciado pelos Incisos I, II e VI, do que no processo de reintegração dele ao adquirir a liberdade. Essa dimensão expressa o interesse de empresas e de órgãos do Estado em explorar a força de trabalho nos presídios e se livrar dos encargos trabalhistas previstos na CLT (Consolidação das Leis Trabalhistas). Uma reportagem divulgada pelo jornal El País informa que $75 \%$ dos detentos que trabalham recebem menos do que o valor previsto na LEP, bem como há milhares trabalhando de graça para "empresas e órgãos governamentais, que, por fora da lei, se beneficiam desta mão de obra vulnerável para baratear seus custos."

[...] Dos 95.919 detentos que são empregados dentro do sistema penitenciário, 33\% (ou 31.653 pessoas) não recebem nada, trabalham de graça [...]. Parte dos contratos feitos entre detentos $e$ empresas no Estado de São Paulo passam pela Fundação Professor Doutor Manoel Pedro Pimentel, a Funap, ligada à SAP [...]. Em São Paulo, Estado com a maior população carcerária do país (240.061 presos), a Secretaria de Administração Penitenciária (SAP) mantêm contratos com 631 empresas privadas e 55 órgãos públicos que utilizam mão de obra dos internos, segundo dados oficiais [...]. No Estado, $27 \%$ dos detentos que trabalham não recebem remuneração alguma, e 53\% recebem menos do que o valor estipulado em lei. (ALESSI, 2017, p.14).

Podemos notar que é estratégico o papel que a FUNAP desempenha no estabelecimento dos contratos, junto às empresas privadas, ao viabilizar a formação profissional e o trabalho no presídio.

De acordo com o PPC (2013), a FUNAP, em sua gênese, tinha como objetivo principal promover ações que levassem à formação profissional do apenado e ao trabalho remunerado dentro das prisões, uma vez que possibilitariam a ressignificação do próprio olhar sobre o preso "numa referência ao fato de que aquelas pessoas recolhidas no sistema prisional eram, também, trabalhadoras e trabalhadores." (PPC, 2013, p. 9).

Podemos observar que a ênfase não era a educação formal, regular, pois esta era prestada e administrada pela Secretaria de Educação do Estado de São Paulo (SEE/SP). Entretanto, objetivando um estreitamento com os estabelecimentos penais, a FUNAP começou a trilhar o caminho da educação e, posteriormente, da defesa jurídica dos presos.

Para Português (2001), a entrada da FUNAP nos sistemas prisionais esteve sujeita à oposição. Conforme relata Goffmam (1974), em uma instituição total, qualquer modificação ou entrada de outra instituição parece estranho ao local e gera contradição e choque de ações, principalmente perturbação na segurança e disciplina. Assim, a FUNAP se confrontou com uma das facetas das instituições totais, esbarrando na impermeabilidade. Moreira (2008) aponta que a dificuldade da FUNAP em adentrar o sistema prisional paulista levou a fundação a assumir várias atividades estranhas aos seus objetivos iniciais, como se fosse uma moeda de troca, algo da própria cultura prisional, um sistema de escambo das ações. Assim, a FUNAP promoveu festas em datas comemorativas, várias atividades culturais, forneceu materiais esportivos e advogados para defender os menos privilegiados economicamente. 
Após a experiência de atuação da FUNAP ter sido considerada exitosa pela própria diretoria da Penitenciária Feminina, o sistema prisional, na época significativamente pequeno, passou a criar diversas oficinas com diferentes ações de trabalho, abrangendo diversas áreas como: marcenaria, metalúrgica, confecção e, principalmente, o artesanato (CANTO, 2008). Atualmente, a FUNAP dispõe de um parque industrial voltado à confecção de móveis escolares, móveis para a SEE/SP, móveis para o metrô, colchões e vestimentas dos funcionários e dos próprios reeducandos presos. (PPC, 2013).

A FUNAP, hoje um braço da SAP, nasceu sob o estigma da laborterapia, já que era necessário ocupar a cabeça do preso, evitando indisciplina, fugas, rebeliões, ou qualquer comportamento que ameaçasse a ordem. Dessa forma, a fundação vinha atuando há mais de trinta anos como autoridade única em relação à educação nas prisões paulistas. A FUNAP executava o maior programa de educação nas prisões existentes no Brasil, tendo que atender a uma população de 219.053 presos em todo Estado de São Paulo, oferecendo ao adulto preso ações complementares de educação, cultura e formação profissional, além das atividades de trabalho. (BRASIL, 2015).

A FUNAP vinha há alguns anos enfrentando forte crise financeira, já que não existia investimento da SEE/SP e do Ministério da Educação (MEC) para sustentar, no sistema Penitenciário Paulista, programas voltados para a qualificação do adulto preso. Por meio do Parecer CNE/CEB n 02 , de 19 de maio de 2010, que dispõe sobre Diretrizes Nacionais para a oferta de educação para jovens e adultos em privação de liberdade nos estabelecimentos penais, o MEC normatiza a oferta de educação nas prisões brasileiras. $O$ art. $3^{\circ}$ da resolução estabelece que a oferta de educação, para jovens e adultos, em estabelecimentos penais

[...] é atribuição do órgão responsável pela educação nos Estados e no Distrito Federal (Secretaria de Educação ou órgão equivalente) e deverá ser realizada em articulação com os órgãos responsáveis pela sua administração penitenciária, exceto nas penitenciárias federais, cujos programas educacionais estarão sob a responsabilidade do Ministério da Educação em articulação com o Ministério da Justiça, que poderá celebrar convênios com Estados, Distrito Federal e Municípios. (BRASIL, 2010, p. 2).

Em outras palavras, esta resolução obrigou a SEE/SP a assumir a educação nos presídios, pois a FUNAP não tinha a autoridade de certificar e gerar documentos referentes à educação formal. Dessa forma, a partir de 2011, houve a movimentação para a transferência e transição da educação "formal", que era executada pela FUNAP, para a SEE/SP. No ano de 2013, a SEE/SP assume definitivamente a educação formal e regular, e os professores da rede estadual assumiram as aulas nas unidades prisionais, trazendo novas características para a educação e para toda a cultura prisional. A execução da educação passa a ter como realidade os Parâmetros Curriculares Nacionais; naquilo que respeita aos conteúdos curriculares e programáticos, as unidades escolares funcionam de forma variada, levando em conta o tipo de unidade prisional. Na maior parte das unidades, as escolas funcionam no período matutino ou vespertino.

Então, coube à FUNAP o papel de assumir a educação para o trabalho nas unidades prisionais. Para isso, a fundação criou o Programa de Educação para o Trabalho (PET) com a finalidade de qualificar o indivíduo preso e, a partir disso, várias entidades com experiência de atuação 
na área educacional estabeleceram parceria com a fundação via terceirização das ações, tais como: SENAC, SENAI, ETECs e Pronatec. (PPC, 2013).

A FUNAP é dividida, no território paulista, em seis gerências regionais. A regional de Presidente Prudente conta com 22 unidades prisionais, incluídas as unidades pesquisadas. As gerências regionais supervisionam os sujeitos envolvidos no processo de educação: monitores, orientadores responsáveis pela prática educacional nas unidades e os monitores de leitura, presos que trabalham como regentes em sala de aula.

\section{O PET: REINSERÇÃO SOCIAL EM UMA SOCIEDADE SEM EMPREGO}

Não podendo mais, por força da lei, executar a educação formal, a FUNAP rapidamente reelabora a sua prática de educação. Para se manter ativa e aceita pelo sistema penitenciário do Estado de São Paulo, criou o PET e, dentro dele, o Projeto intitulado De olho no futuro, conforme especificada na norma da Diretoria Executiva do projeto:

[...] 09. O Programa de Educação para o Trabalho tem por objetivo contribuir para Inclusão social de pessoas em privação de liberdade, por meio do desenvolvimento de competências e habilidades que ampliem as possibilidades de inserção no mundo do trabalho, geração de renda e participação na sociedade. [...]

09.2. O Projeto Trabalho e Educação: de olho no Futuro será desenvolvido em Curso livre, com estrutura modular flexível, com 10 (dez) módulos, podendo ser cursado sem a exigência do grau de escolaridade.

09. 3. Será ministrado em três etapas:

09.3.a. "Ser - Desenvolvimento Pessoal", buscando desenvolver habilidades de comunicação, entendimento da importância da cultura e do mundo do trabalho e da capacidade de entender e superar as adversidades visando uma convivência social mais integrada e harmoniosa;

09.3.b. "Fazer-Desenvolvimento Profissional", como forma de melhorar a compreensão do mundo do trabalho, suas mudanças e consequências, as possibilidades profissionais, a importância da formação profissional, da iniciativa e a necessidade de elaboração de Projeto de vida Profissional;

09.3.c." Conviver - Desenvolvimento social", procurando o reconhecimento das atividades de responsabilidade social com relação ao meio ambiente sustentabilidade, a convivência sócia comunitária e' nos aspectos relacionados à conduta ética, cidadania e participação Política. [...]. (PROJETO PEDAGÓGICO DO CURSO, 2013).

Notamos que o modelo de educação profissional, proposto no âmbito do PET, segue a tendência hegemônica dos programas oficiais de formação básica e profissional, que se pautam nas competências e habilidades, responsabilizando o indivíduo pela entrada no mundo do trabalho que deve se tornar adaptável às suas transformações. Em conformidade com essa concepção, emerge a defesa do empreendedorismo como discurso estratégico para a solução do desemprego estrutural e como saída da criminalidade, já que compete exclusivamente a cada indivíduo, enquanto promotor social de si mesmo, saber vender-se e realocar-se no mercado, criando as possibilidades de inserção social para que não haja reincidência na criminalidade. 
Ele pretende possibilitar ao reeducando o egresso ao mercado de trabalho ao sair de liberdade, possibilitando uma vida diferente longe do crime tendo um trabalho formal às vezes tendo o seu próprio empreendimento trabalhando como autônomo. (COORDENADORA DE PROJETO).

O conceito de empreendedorismo, utilizado no PPC (2013), revela a tentativa de conformação do trabalhador desempregado ou aceitação do trabalho precário ao se aventurar de forma autônoma, sem nenhuma garantia social, no universo da informalidade e em atividade laborativa rejeitada pela maioria dos trabalhadores. Esse fato pode ser atestado segundo a afirmação do Diretor de Educação, a seguir:

São para todos os trabalhos, mas dentro dos presídios a gente sabe que infelizmente os trabalhos que são introduzidos nos presídios são aqueles que a população e a sociedade não estão dispostas a executar, aquela que o empresário tem dificuldade de encontrar mão de obra é trabalho com pouca desenvoltura [cita construção civil, pizzaiolo]. (DIRETOR DE EDUCAÇÃO).

Por se tratar de educação profissional para pessoas privadas de liberdade, a perspectiva de responsabilização individual agrava-se, porque tratam-se de pessoas historicamente excluídas do processo de formação em geral e, portanto, sendo esses cursos de curta duração, ocorre a impossibilidade de uma formação mais complexa, conforme o paradigma tecnológico vigente. A preparação nas unidades prisionais gera um trabalho rejeitado pela sociedade e menos qualificado, o qual pressupõe intensa exploração da força de trabalho, submetida à mais-valia absoluta (BRUNO, 2011), e que pode ser comparada, inclusive aos sistemas de escravidão. Em toda essa dinâmica, é possível atestar o estigma social plasmado na pessoa que cumpriu a pena, e isso dificulta "vender-se" para os sistemas de trabalho.

Nessa perspectiva, Dolabela (2008, p.42) descreve a dimensão do empreendedorismo de si como: "Empreendedor é alguém que imagina, desenvolve e realiza uma visão. Em outras palavras, acredita que pode realizar seu próprio sonho, julgando-se capaz de mudar o ambiente em que está inserido." A partir da descrição de Dolabela (2008) pode-se compreender que "empreender" relacionase, sobretudo, à capacidade de modificar o ambiente, na medida em que se vive inserido na complexidade do mundo do capital. Tudo isso remete à responsabilização do indivíduo: pelo seu sucesso produtivo, pela ampliação dos postos de trabalho e pelo próprio fracasso, caso não consiga sobreviver diante dessa realidade.

O conceito de empreendedorismo de Dolabela (2008) estaria equivocado para Sabino (2010), ao impedir que os indivíduos questionem a forma econômica social de produção e reprodução, sem refletir sobre a natureza destrutiva do capital. Para Sabino (2010), não há uma escolha possível no empreendedorismo, apenas a aceitação definitiva desse modelo econômico, sem questionar as suas imperfeições, uma vez que questionar é perder tempo e é preciso trabalhar arduamente para vencer o desafio empreendedor escolhido.

O empreendedorismo expresso no PPC do PET indica a aceitação e a adaptação ao mundo precarizado do trabalho, e em nada se relaciona ao empreendedor social, como imagina Dolabela 
(2008), porque o que está no horizonte da formação para o trabalho, praticada nos presídios, é a exploração da força de trabalho simples e informal.

Eu percebo que é uma coisa (o PET) mais voltada ao empreendedorismo, para que a pessoa possa ser autônoma, que ela saiba se virar diante da crise. É uma ferramenta que ele pode estar utilizando lá fora, sem estar vinculado a uma empresa, tudo que ele aprende no PET, vai dar um suporte para que possa, não só, para o trabalho formal, mas o trabalho informal, pois se ele não tiver acesso ao trabalho formal ele está capacitado para o trabalho informal. (MONITORA DO CR)

Os idealizadores e os executores do PET compreendem que há uma grande transformação no mundo do trabalho e que é preciso, então, desenvolver uma adaptação para a sobrevivência na sociedade contemporânea, por isso estão previstas habilidades voltadas para a aceitação, prontidão, disciplina, plasticidade diante da possibilidade concreta de desemprego, assim como consta no PPC do curso, ao enfatizar a dimensão do "ser, fazer, conviver", citada anteriormente (PPC, 2014).

Contemplar um módulo de empreendedorismo e habilidades, como flexibilidade e criatividade, indicam a necessidade de buscar maneiras para sobreviver na informalidade. Julião (2011) defende essa maneira de pensar e observa que o mais importante é o trabalho decente, ainda que informal, uma vez que a economia informal "vem apontando caminhos para a garantia do bom emprego, indispensáveis para a compreensão da sociedade moderna [...].” (JULIÃO, 2011, p.193). Podemos inferir, portanto, que essa é a ideologia que norteou a construção do PET.

Com base em Antunes (2011) e Wacquant (2011), averiguamos que a onda punitiva nos países que adotaram o neoliberalismo, conduzindo grande parte dos indivíduos para o encarceramento, devese justamente ao desemprego em massa e à imposição do trabalho assalariado precário. Wacquant (2011, p. 114) demonstra que existem cerca de 40 estudos empíricos, em várias sociedades capitalistas, sinalizando para a "[...] estreita e positiva correlação entre a deterioração do mercado de trabalho e o aumento efetivo dos presos." Diante disso, e a partir dos mesmos estudos, os fatos indicaram não haver correlação entre o índice de criminalidade e encarceramento. (WACQUANT, 2011).

O PET, ao mesmo tempo que objetiva a acomodação e aceitação ao trabalho precário, sustenta-se na ideia de empreendedorismo como reconhecimento implícito da dificuldade de reinserção dos indivíduos privados de liberdade no mercado formal de trabalho. Essa dificuldade de reinserção tende a ser agravada pelo estigma social atribuído a esses indivíduos e à baixa qualificação da força de trabalho.

Com o intuito de averiguarmos a relação que o PET propõe estabelecer com o mundo do trabalho, questionamos os entrevistados a respeito de que tipo de trabalho o programa almeja desenvolver a fim de inserir os presos. Pode-se detectar a contradição nas falas dos entrevistados e a dificuldade que o PET tem para atingir o objetivo proposto, em decorrência, principalmente da dificuldade de absorção pelo mercado de trabalho, mas também da insuficiência da formação oferecida. Pode-se perceber alguns desses aspectos do programa na afirmação a seguir: "É uma forma 
dele sair daqui com melhores condições de concorrer ao mercado de trabalho, um currículo mais rico e como suportar lá fora, é uma coisa que agrega que acrescenta na vida." (MONITORA DO CR).

Além disso, evidenciou-se que a concepção de trabalho, que direciona a atuação dos educadores monitores e gestores do PET, foi extraída e restringe-se à lógica do mercado de trabalho e não se relaciona ao trabalho como meio de desenvolvimento humano e com potencial educativo.

Com base nas entrevistas, e ao analisarmos o PPC (2013), notamos a contradição em relação à ideia de inclusão, difundida pelo programa, e a dificuldade concreta de inserção do preso no mundo do trabalho. Não se vislumbra efetivamente a reinserção e a reabilitação do indivíduo privado de liberdade tal como apregoado no discurso, até porque os entrevistados revelam que o objetivo do programa é preparar tais indivíduos para o mundo do desemprego, o trabalho "autônomo" ou "informal".

$\mathrm{Na}$ realidade, o referido Programa, os depoimentos dos gestores e dos monitores reconhecem a dificuldade de reinserção dos indivíduos em liberdade e, por essa razão, afirmam que os detentos deverão estar preparados para lidar com o preconceito, o desemprego, a discriminação, a segregação e, principalmente, a marginalização social. Nesse sentido, é compreensível a preocupação do PET em estabelecer como pilares da formação, no Programa De olho no futuro, as competências voltadas para a adaptação social, expressas nas concepções "saber ser", "saber fazer" e "saber conviver."

O aspecto essencial na formação está relacionado à dimensão ideológica de aceitação, adaptação e adequação comportamental aos valores do mercado, tal como enfatizam os objetivos a serem alcançados: "postura ética-cidadã responsável socialmente, atitude empreendedora, mudanças comportamentais significativas, afetando a forma de pensar e agir em sociedade e no ambiente de trabalho (PPC, 2014). O saber fazer não é a preocupação do programa, uma vez que há o reconhecimento de que não haverá reinserção social efetiva. Assim, podemos dizer que não haverá alteração substancial no modo de vida dos detentos quando estiverem em liberdade.

Diante da impossibilidade de inserção produtiva no mundo do trabalho, há, para Wacquant (2011), o encarceramento dos pobres e a configuração das prisões como espaços de confinamento. Nessa perspectiva, qualquer projeto de reabilitação e reinserção é inviabilizado.

Em termos claros, embora a sua vocação não resida nisso e ela não tenha nem competência e nem meio para isso, a polícia deve daqui em diante fazer a tarefa que o trabalho social não faz ou já não faz mais desde que se admite que não há (e haverá) trabalho para todos. À regulamentação da pobreza permanente pelo trabalho assalariado sucede sua regulamentação pelas forças da ordem e pelos tribunais. (WACQUANT, 2011, p. 137).

A seguir, consta a quantidade de alunos e cursos de qualificação executados no ano de 2015 , pela FUNAP, nas unidades pesquisadas.

Tabela 1: Quantidade de detentos atendidos no PET por unidade prisional

Programa de Educação para o Trabalho e Cidadania (PET) 


\begin{tabular}{|l|c|c|c|c|l|l|l|}
\hline \multicolumn{2}{|c|}{ Cursos de Qualificações Profissionais } \\
\hline $\begin{array}{l}\text { Unidade } \\
\text { prisional: }\end{array}$ & $\begin{array}{l}\text { População } \\
\text { carcerária }\end{array}$ & $\begin{array}{l}\text { Curso } \\
\text { PET }\end{array}$ & $\begin{array}{l}\text { Curso } \\
\text { PET\% }\end{array}$ & Parceiro & Cursos: & $\begin{array}{l}\text { Quantidade/ } \\
\text { Alunos: }\end{array}$ & \% Alunos \\
\hline & 1228 & 20 & 1,6 & SENAI & Padeiro & 16 & $1,3 \%$ \\
Penitenciária & & 20 & 1,6 & & Pizzaiolo. & 16 & $1,3 \%$ \\
\cline { 3 - 4 } de Presidente & & Total: & Total\%: & & & Total: 32 & Total \% 2,6 \\
Prudente & & 40 & 3,25 & & & & \\
\hline
\end{tabular}

Fonte: FUNAP (2015b). Elaborado pelos autores

Tabela 2: Quantidade de detentos atendidos no PET por unidade prisional

\begin{tabular}{|l|c|c|l|l|l|l|c|}
\hline \multicolumn{7}{|c|}{ Programa de Educação para o Trabalho e Cidadania (PET) } \\
\hline $\begin{array}{l}\text { Unidade } \\
\text { prisional: }\end{array}$ & $\begin{array}{c}\text { Populaçã } \\
\text { o } \\
\text { carcerária }\end{array}$ & $\begin{array}{l}\text { Curso } \\
\text { PET }\end{array}$ & $\begin{array}{l}\text { Curso } \\
\text { PET \% }\end{array}$ & Parceiro: & Cursos: & $\begin{array}{l}\text { Quantidad } \\
\text { e Alunos: }\end{array}$ & $\begin{array}{l}\text { Quantidade } \\
\text { alunos: \% }\end{array}$ \\
\hline $\begin{array}{l}\text { Centro de } \\
\text { Ressocialização }\end{array}$ & 226 & 12 & 5,2 & Neotrópica & Elétrica & 25 & $11 \%$ \\
$\begin{array}{l}\text { Presidente } \\
\text { Prudente }\end{array}$ & 11 & 4,8 & & Hidráulica & 25 & $11 \%$ \\
\cline { 2 - 7 } & & Total & Total: \% & & & & \\
\hline
\end{tabular}

Fonte: FUNAP (2015b). Elaborado pelos autores

Ao observarmos as tabelas, constatamos que é insignificante a população carcerária atendida pelo projeto nas unidades prisionais. Na Penitenciária de Presidente Prudente (Tabela 1) é atendida apenas $3,25 \%$ da população carcerária (40 presos), e nos cursos de qualificação, sequência do PET, é atendida apenas $2,6 \%$ (32 presos).

É importante observar que, no ano de 2015, tiveram apenas dois cursos de qualificação profissional para um universo de 1.228 presos, ou seja, quantidade insuficiente para atender à totalidade da população carcerária. Os cursos foram de padeiro e de pizzaiolo, ambos com 16 alunos em cada turma (1,3\%), perfazendo um total de 32 internos, ou seja, $2,6 \%$ do total da população carcerária é atendida.

Por meio da observação nas unidades prisionais, e na FUNAP, verificamos que não há infraestrutura suficiente para atender um maior número de presos, visto que todas as salas são ocupadas com as aulas destinadas à formação regular. É importante relatar que as aulas do PET, na penitenciária de Presidente Prudente, são realizadas em uma sala de aula multifuncional, destinada ao ensino regular, a qual funciona, também, como sala de vídeo, e é utilizada pelos professores do sistema público estadual de ensino. Portanto, não há espaço específico e apropriado para a realização do PET. Observamos, ainda, que o projeto PET era realizado na galeria ${ }^{3}$ da unidade prisional, local em

\footnotetext{
${ }^{3}$ Local em que dá acesso a todo pavilhões das unidades prisionais e por ele que também se entra e sai das unidades prisionais.
} 
que os internos passam constantemente conversando, fato que dificulta a realização do projeto. A ausência de sala própria para o projeto é um dos elementos que indica a falta de condições mínimas para aprendizagem.

No Centro de Ressocialização, por ser uma unidade diferenciada e atender uma população carcerária menor, podemos observar maior número de alunos atendidos. Em um universo de 226 internos, 23 realizam o projeto PET, que corresponde a 10\% da população carcerária. No ano de 2015 , foram ofertados apenas dois cursos de qualificação profissional, realizados na referida unidade prisional, como demonstra a Tabela 2, sendo eles: Hidráulica, com 25 internos (11\% da população carcerária) e outro de Elétrica, com 25 internos (11\% da população carcerária), perfazendo um total de 50 internos, ou $22 \%$ da população total.

De acordo com a FUNAP (2015b), pudemos verificar que os cursos apresentados acima eram apenas de doze horas de duração. A reduzida duração dos cursos evidencia que não há condições mínimas para aprendizagem de um ofício profissional, seja ele qual for, corroborando com os demais dados, analisados anteriormente, que indicam que a formação profissional, em especial na dimensão do saber fazer, efetivamente não se realiza no PET. Dada a ausência de oferta da educação profissional, o que sobressai é a cooptação ideológica expressa nas dimensões do "saber ser" e "saber conviver", ambas descoladas da inserção na materialidade da vida produtiva.

Ele é bem aberto, ele forma para a postura profissional e não para um tipo de trabalho [...], mas o nosso maior parceiro é o SENAl, infelizmente ele acaba se limitando nessa situação da construção civil, não tem outras opções quando é diferente é de pizzaiolo e padeiro. (COORDENADORA DE PROJETO).

A insuficiência da formação técnica ofertada (saber fazer) direciona o discurso dos executores do PET para a potencialização da dimensão subjetiva de predisposição para a adaptação às transformações do mercado. Assim, a qualificação ofertada não garante conhecimentos técnicos que habilitem os educandos a dominar um ofício, garantindo apenas uma "postura profissional", que pode ser traduzida em noções gerais de um ofício e ênfase na responsabilização do indivíduo pelo seu sucesso ou fracasso.

\section{CONCLUSÃO}

Historicamente, as prisões surgiram como instituição de controle social (FOUCAULT, 2002), com o intuito de qualificar e pacificar os pobres, miseráveis, mendigos, crianças e prostitutas que perambulavam pelas ruas das antigas metrópoles europeias com o advento do capitalismo e o declínio do sistema feudal. A prisão, enquanto instituição de controle e de punição, não mudou significativamente desde a sua gênese até a atualidade, apesar das conquistas no âmbito dos direitos humanos. Tais conquistas foram impulsionadas pela Declaração Universal dos Direitos Humanos (1948), pelo atendimento de seus princípios em inúmeras cartas constitucionais dos estados nacionais, como é o caso do Brasil (BRASIL, 1988), e pelas regulamentações específicas em relação à educação nos presídios, como indicamos. 
Entretanto, a educação para o trabalho, materializada no sistema penitenciário do estado de São Paulo, por meio da atuação da FUNAP com a criação do PET, tem se pautado na intensificação do trabalho precário e na qualificação profissional simples, de menor valor agregado. A análise evidenciou que a formação profissional não se efetiva nas unidades prisionais, sobretudo, em decorrência da reduzida carga horária dos cursos, da ausência de infraestrutura para as atividades de estudo e do reduzido percentual de detentos atendidos pelo PET. Assim, a ênfase da formação profissional não está no saber fazer o ofício, mas na inculcação ideológica voltada para a adaptação à sociedade excludente do capital. A concepção de empreendedorismo, que perpassa essa formação, revela o reconhecimento da impossibilidade de inserção social e produtiva do contingente expressivo de detentos no mundo do trabalho.

Evidencia-se, portanto, que o trabalho direcionado ao indivíduo privado de liberdade é aquele que a sociedade rejeita. Em outras palavras, com base nas entrevistas com os monitores e os gestores, podemos inferir que o programa prepara o indivíduo para a própria segregação social, na medida em que há incerteza a respeito da sobrevivência e inserção produtiva e social dos internos ao conquistarem a liberdade.

A ideia de inclusão que perpassa o PET desconsidera a sociedade como totalidade, já que não se trata de estar "fora" da sociedade e precisar adentrá-la, e sim reconhecer que o indivíduo privado de liberdade está integrado na sociedade capitalista em condição subordinada, desigual e marginalizada.

\section{REFERÊNCIAS}

1. ALESSI, Gil. O lucrativo negócio de empregar presos de graça ou pagando menos do que a lei determina. El País, 20 dezembro, p.13-14, 2017. Disponível

em: <https://brasil.elpais.com/brasil/2017/12/14/politica/1513259606_735347.html > Acesso em: 30.10. 2018.

2. ANTUNES, Ricardo. Adeus ao trabalho? 15. ed. São Paulo: Cortez, 2011.

3. BRASIL. [Constituição (1988)]. Constituição da República Federativa do Brasil. 21. ed. São Paulo: Saraiva, 1999.

4. BRASIL. Ministério da Justiça. Departamento Penitenciário Nacional. Síntese das ações do Departamento Penitenciário: ano 2017. Brasília: DEPEN, 2017.

5. BRUNO, Lucia. Educação e desenvolvimento econômico no Brasil. Revista Brasileira de Educação, v.16, n.48, set-dez. 2011. p. 545-562.

6. CANTO, Liberdade. Fundação Manoel Pedro Pimentel. São Paulo: Imprensa Oficial, 2008. 
7. CARREIRA, Denise; CARNEIRO, Suelaine. Relatoria Nacional para o Direto Humano à Educação: educações nas prisões brasileiras. São Paulo: Plataforma DhESCA Brasil, 2009.

8. CONSELHO NACIONAL DE EDUCAÇÃO. Parecer CNE/CEB n 2/2010. Diretrizes Nacionais Para a oferta de Educação de Jovens e Adultos em Situação de Privação de Liberdade nos Estabelecimentos Penais. Brasília, DF: MEC/CNE/SECAD, 2010.

9. DOLABELA, Fernando. Oficina do empreendedor. São Paulo: Sextante, 2008.

10. FOUCAULT, Michel. Vigiar e punir. 26. Ed.Trad. Raquel Ramalhete. Petrópolis: Vozes, 2002.

11. FUNAP. Fundação "Prof. Dr. Manoel Pedro Pimentel", Disponível em: <www.funap.sp.gov.br>. Acesso em: 15 nov. $2015 a$.

12. FUNAP. Fundação "Dr. Manoel Pedro Pimentel". Relatório Mensal Consolidado, (RMC), São Paulo, SP: FUNAP, 2015b.

13. GOFFMAM, Erving. Manicômios, prisões e conventos, São Paulo: Perspectiva, 1974.

14. JULIÃO, Elionaldo Fernandes. A ressocialização através do estudo e do trabalho no sistema penitenciário brasileiro. 2009. Paginas 450. Tese (Doutorado em: Ciências Sociais Aplicada\} Instituto de Filosofia e Ciências Humanas, Universidade do Estado do Rio de Janeiro, Rio de Janeiro, RJ. Educação e trabalho como programas de "reinserção social". Espaço da prisão e suas práticas educativas: enfoques e perspectivas contemporâneas. São Carlos: Edufscar, 2011. p. 191222. LEITE, Jose Ribeiro. Educação por traz das grades: uma contribuição ao trabalho educativo, ao preso e a sociedade. 1997.páginas 255 Dissertação (Mestrado em Educação) - Universidade Estadual Paulista, Marília, SP.

ONOFRE, Elenice Maria Cammarosano. Educação Escolar entre as Grades. São Carlos: Edufscar, 2007. . Processos educativos em espaços de privação de liberdade. Revista Educação, Campinas, SP n. 27, p. 67-74, jul./dez. 2009.

19. PORTUGUES, Manoel Rodrigues. Educação de adultos presos: possibilidades e contradições da inserção da educação escolar nos programas de reabilitação do sistema penal no Estado de São 
Paulo. 2001. Dissertação (Mestrado em Educação) - Faculdade de Educação, Universidade de São Paulo, São Paulo, 2001. doi:10.11606/D.48.2001.tde-12022015-141319. Acesso em: 2019-07-02.

SABINO, Geruza Tomé. "Empreendedorismo: reflexões críticas sobre o conceito no Brasil." Anais Seminário do Trabalho 7 (2010): 1-16. Disponível em: <http://www.estudosdotrabalho.org/anais-vii7-seminario-trabalho-ret-

2010/Geruza_Tome_Sabino_Empreendedorismo_reflexes_crticas_sobre_o_conceito_no_Brasil.pdf. > Acesso em: 04 mai. 2016.

21. SILVA Junior, João Ferreira da. O significado e as contradições da educação para o trabalho nas penitenciárias do estado de São Paulo, desenvolvidos pela fundação “Professor Doutor Manoel Pedro Pimentel" (FUNAP). 2016. p.180. Dissertação (Mestrado em Educação) - Universidade do Oeste Paulista, Presidente Prudente, São Paulo, 2016.

22. VARELA, Drauzio. Estação Carandiru. São Paulo: Companhia das Letras, 1999.

WACQUANT, Loic. Punir os pobres. Rio de Janeiro: Zahar, 2007. As prisões da miséria. Rio de Janeiro: Zahar, 2011.

25. WATANABE, Marta. Presídios geram negócios e empregos no interior de SP, São Paulo/SP. Valor Econômico, Especial, 07 dez. 2011 p. A14. Disponível em: $<$ http://www2.senado.leg.br/bdsf/bitstream/handle/id/468240/noticia.htm?sequence=1>. Acesso em: 11 jan. 2016.

\section{João Ferreira Silva Jr}

Mestre em Educação pela UNOESTE. Graduado em Letras pela Universidade do Oeste Paulista e em Pedagogia (FAPEPE). Pós graduado em nível de especialização e mestrado. Atua como funcionário público do sistema penitenciário no estado de São Paulo. Investiga os temas: educação em situação de privação de liberdade, neoliberalismo e encarceramento.

\section{Erika Porceli Alaniz}

Pós-doutora em Educação pela Faculdade de Filosofia e Ciências da Universidade Estadual PaulistaUNESP, Campus de Marília; Doutora em Educação pela Faculdade de Educação da Universidade de São Paulo- FEUSP. Docente da graduação em Pedagogia, Licenciatura em Geografia e do Programa de Pós-Graduação, Mestrado Profissional em Educação da Universidade Estadual do Mato Grosso do 
Sul (UEMS), campus de Campo Grande, MS. Desenvolve estudos na área de Política educacional, atuando principalmente nos seguintes temas: qualificação profissional, autogestão, movimentos sociais e educação e trabalho.

\section{Como citar este documento:}

SILVA JR, João Ferreira; ALANIZ, Erika Porceli. A educação para o trabalho nos sistemas prisionais paulistas. Reflexão e Ação, Santa Cruz do Sul, v. 28, n. 2, jun. 2020. ISSN 1982-9949. Disponível em: <https://online.unisc.br/seer/index.php/reflex/article/view/12642>. Acesso em: doi:https://doi.org/10.17058/rea.v28i2.12642. 